\title{
Comparative phylogenetic analysis of cystatin gene families from arabidopsis, rice and barley
}

\author{
Manuel Martínez, Zamira Abraham, Pilar Carbonero and Isabel Díaz
}

\author{
Arabidopsis $\cdot$ Barley $\cdot$ Phylogenetic \\ analysis $\cdot$ Plant cystatin $\cdot$ Rice
}

\begin{abstract}
The plant cystatins or phytocystatins comprise a family of specific inhibitors of cysteine proteinases. Such inhibitors are thought to be involved in the regulation of several endogenous processes and in defence against pests and pathogens. Extensive searches in the complete rice and Arabidopsis genomes and in barley EST collections have allowed us to predict the presence of twelve different cystatin genes in rice, seven in Arabidopsis, and at least seven in barley. Structural comparisons based on alignments of all the protein sequences using the CLUSTALW program and searches for conserved motifs using the MEME program have revealed broad conservation of the main motifs characteristic of the plant cystatins. Phylogenetic analyses based on their deduced amino acid sequences have allowed us to identify groups of orthologous cystatins, and to establish homologies and define examples of gene duplications mainly among the rice and barley cystatin genes. Moreover, the absence of a counterpart between the two monocots, as well as strong variations in the motifs that interact with the cysteine proteinases, may be related to a species-specific evolutionary process. This cystatin classification should facilitate the assignment of proteinase specificities and functions to other cystatins as new information is obtained.
\end{abstract}

\section{Introduction}

The cystatins constitute a superfamily of evolutionarily related proteins, which are reversible inhibitors of papain-like cysteine proteinases (Brown and Dziegielewska 1997) and have been identified in vertebrates, invertebrates and plants. Those from plants-referred to as phytocystatins (PhyCys) have been claimed to be an independent family, containing a particular consensus motif [LVI]-[AGT]-[RKE]-[FY]-[AS]-[VI]-x-[EDQV][HYFQ]- $\mathrm{N}$ found in the region corresponding to a predicted N-terminal $\alpha$-helix (Margis et al. 1998), and they cluster on a distinct branch from other cystatin families on the phylogenetic tree. In addition to this consensus, the PhyCys contain three motifs that are involved in the interaction with their target proteinases: (1) the activesite motif $\mathrm{QxVxG}$; (2) a $\mathrm{G}$ near the N-terminus; (3) a conserved $\mathrm{W}$ in the second half of the protein. The best studied cystatin is OC-I from rice (Oryza sativa), which shares with other members of the cystatin superfamily a common structure comprising five-stranded antiparallel $\beta$-sheets wrapped around a central $\alpha$-helix (Nagata et al. 2000). Most PhyCys have a molecular mass in the $12-16-\mathrm{kDa}$ range and no disulphide bonds. However, so-called multicystatins of $\approx 85 \mathrm{kDa}$ from potato and tomato containing eight similar cystatin domains (Waldrom et al. 1993; Wu and Haard 2000), and cystatins from soybean, cabbage, sesame, and strawberry of $\approx$ $23 \mathrm{kDa}$ with a longer C-terminal end ( $\mathrm{Lim}$ et al. 1996; Misaka et al. 1996; Shyu et al. 2004; our unpublished results) have also been described. Moreover, a putative signal peptide has been found in several PhyCys, suggesting that they are targeted to the endoplasmic reticulum.

PhyCys have been implicated in the regulation of endogenous and heterologous cysteine proteinases (Arai et al. 2002; Haq et al. 2004). Their endogenous role has been related to the inhibition of endogenous cysteine proteinases - which prevents degradation of storage proteins in developing endosperms - and the regulation 
of protein turnover upon seed germination (Arai et al. 2002; Corre-Menguy et al. 2002; Martínez et al. 2003b) and of programmed cell death (Solomon et al. 1999; Belenghi et al. 2003). Their defence role is inferred from their ability to inhibit exogenous proteases such as those present in the digestive tracts of insects, by their activity in bioassays against insects and mites (Kuroda et al. 1996; Pernas et al. 1998, 2000) and by the enhanced resistance to insects, nematodes, slugs and potyviruses observed in transgenic plants overexpressing PhyCys genes (Vain et al. 1998; Gutierrez-Campos et al. 1999; Walker et al. 1999; Delledonne et al. 2001; Atkinson et al. 2003). Antifungal activities have also been described for certain PhyCys (Pernas et al. 1999; Siqueira-Junior et al. 2002; Soares-Costa et al. 2002; Martínez et al. 2003a). Although the mode of action of these PhyCys against phytopathogenic fungi has not yet been fully established, it is worth mentioning that Martínez et al. (2003a) have reported that the inhibition of Botrytis cinerea by the barley cystatin $\mathrm{HvCPI}$ is actually not dependent upon its ability to inhibit cysteine proteinases.

Although PhyCys seem to be involved in important physiological processes, a systematic analysis of the cystatin gene family in plant species has not yet been performed. To date, only one cystatin gene has been characterized in most plant species; exceptions include wheat, where five genes have been described (CorreMenguy et al. 2002; Kuroda et al. 2001). The genome sequence of Arabidopsis was completed in 2002 (The Arabidopsis Genome Initiative 2000) and sequence drafts of good quality are available for the two subspecies japonica and indica of rice (O. sativa; Goff et al. 2002; Yu et al. 2002). Arabidopsis and $O$. sativa serve as models for dicotyledoneous and monocotyledoneous species, respectively, and the genomic sequence data available can be used to identify the cystatin genes in these species.

In barley, we have characterized cDNA and genomic clones encoding the cystatin Hv-CPI (hereafter referred to as HvCPI-1; gene Icy). The corresponding gene is expressed in seeds and is induced in vegetative tissues by abiotic and biotic stresses; it has a single intron in its ORF and is the orthologue of the rice gene that codes for the cystatin OC-II (Gaddour et al. 2001; Martínez et al. 2003b, 2005). The publicly available collection of EST from barley (the genome sequence of which has not yet been completed), complied by the Genomics Institute at Clemson University (CUGI), is a useful tool for annotating new members of the cystatin gene family in this species which belongs to the Triticeae.

In this study, using bioinformatic resources, we annotate the PhyCys families in barley, rice and Arabidopsis. The phylogenetic analysis has allowed us to identify paralogous genes and clusters of orthologous groups as the basis for further characterization of cystatin genes of unknown function. These data also allow us to propose evolutionary models based on the phylogenetic relationships among these plant species.

\section{Materials and methods}

Rice and Arabidopsis genome sequences

Searches for rice and Arabidopsis cystatin genes were carried out in publicly available genome databases. Sequences for Oryza sativa ssp. japonica were obtained from the International Rice Genome Sequencing Project (IRGSP) at The Institute for Genomic Research (TIGR; http://www.tigr.org). Cystatin gene sequences in Arabidopsis thaliana were identified by searching The Arabidopsis Information Resource (TAIR) database (http:// www.Arabidopsis.org). In both cases WU-Blast 2.0 was used with default parameters. Sequences for Oryza sativa ssp. indica were obtained from the Whole Genome Shotgun Sequencing Project of the Beijing Genomics Institute at the NCBI (http://www.ncbi.nlm.nih.gov/ BLAST/Genome/PlantBlast.html) and searched using default parameters.

\section{Barley ESTs}

Searches for new barley cystatin genes were performed in publicly available barley EST libraries using the Protein query-Translated database (tblastn) program with default parameters. Selected ESTs were obtained from the cDNA libraries constructed for Hordeum vulgare L. by The Clemson University Genomics Institute, Clemson, S.C. (CUGI, http://www.genome.clemson.edu/projects/barley). Nucleotide sequences were determined on both strands using vector-specific primers and an automated DNA sequencer (ABI PRISM TM 3100; Applied Biosystems).

\section{Sequence analysis}

Alignments of protein sequences were performed at the DNA Data Bank of Japan (http://www.ddbj.nlg.ac.jp) using the CLUSTALW program (Higgins et al. 1994) with default parameters. Signal peptide analysis was performed using the SignalP Version 3.0 (http:/) www.cbs.dtu.dk/services/SignalP) program (Bendtsen et al. 2004). Bootstrapping analysis with a PHYLIP 'format tree' output was carried out after construction of trees by the neighbour-joining method, and the trees were represented using TREEVIEW (Version1.6.6) software (Page 1996). Conserved motif analysis was performed by means of the MEME (http://meme.sdsc.edu) program (Bailey and Elkan 1994) using default settings, except that the minimal and maximal motif widths were set to 8 and 12 amino acids, respectively, and the maximum number of motifs to find was defined as 50 .

\section{Digital northern analysis}

Searches for EST sequences corresponding to the barley, rice and Arabidopsis cystatins were made in the 
GenBank EST database (dbEST, http:// www.ncbi.nlm.nih.gov/dbEST/index.html) using the tblastn program and default parameters. The entries identified were checked for tissue origin at the GenBank nucleotide sequence database.

\section{Results}

Identification of cystatin genes from Arabidopsis, rice and barley

In order to assemble a complete and non-redundant set of the cystatin genes in Arabidopsis and rice, we adopted an in silico approach, initially screening the genome sequences of Arabidopsis thaliana and Oryza sativa ssp. japonica. Full-length sequences of different cystatin proteins containing the conserved domains characteristic of PhyCys (the LARFAV-like motif, the QxVxG motif and the tryptophan in the C-terminal region) that were available at the time of the analysis were used to perform independent Blast searches in the TIGR rice database and the TAIR Arabidopsis database. In both cases, sequences showing similarity to the main domains of PhyCys and an expectation value $<1.0 \times 10^{-5}$ were considered to be true cystatins. Blast searches were then repeated with each new cystatin sequence found in the rice and Arabidopsis databases to complete the cystatin collections. Twelve non-redundant cystatin sequences were found in rice (OC-I to OC-XII) and seven (AtCYS1 to AtCYS-7) were identified in Arabidopsis (Fig. 1). Based on these sequences, several barley EST collections were used to perform independent tblastn searches at the DNA Databank of Japan. A total of seven non-redundant EST sequences corresponding to proteins HvCPI-1 to HvCPI-7, were found in the EST collection for the $\mathrm{cv}$ Morex established by CUGI (Table 1). One of these (HvCPI-1) was previously annotated and characterized from the cultivar Bomi (Gaddour et al. 2001; Martínez et al. 2003a, 2003b, 2005). The genomic sequence of $O$. sativa ssp. indica was also screened using the cystatin sequences previously obtained. As in the japonica genome, 12 genes for cystatins were identified in indica. Comparison of the predicted proteins shows minor amino acid variations in 8 out of the 12 allelic pairs, which were confined to the signal peptides and other less conserved regions. In the following, only the japonica dataset is considered.

\begin{tabular}{|c|c|c|c|}
\hline $\begin{array}{l}\text { Gene } \\
\text { name }\end{array}$ & Locus id & $\begin{array}{c}\text { Predicted gene } \\
\text { structure }\end{array}$ & $\begin{array}{c}\text { Amino } \\
\text { acids }\end{array}$ \\
\hline OC-I & Os01g58890 & NVT & $\overline{139}$ \\
\hline OC-II & Os05g41460 & $\mathbf{N}$ & 156 \\
\hline OC-III & Os05g33880 & $\mathbf{T}$ & 150 \\
\hline OC-IV & Os01g68660 & & 158 \\
\hline OC-V & Os01g68670 & $\square \mathbf{N}$ & 147 \\
\hline OC-VI & Os03g11180 & & 113 \\
\hline OC-VII & Os03g11170 & & 117 \\
\hline OC-VIII & Os03g31510 & & 123 \\
\hline OC-IX & Os03g11160 & & 114 \\
\hline OC-X & Os04g28250 & & 156 \\
\hline OC-XI & Os09g08100 & & 120 \\
\hline OC-XII & Os01g16430 & $\mathbb{N})_{109}$ & 250 \\
\hline AtCYS-1 & At5g12140 & $\mathbf{N}$ & 101 \\
\hline AtCYS-2 & At2g31980 & $\mathbf{N}$ & 147 \\
\hline AtCYS-3 & At2g40880 & $\mathbf{N}$ & 125 \\
\hline AtCYS-4 & At4g16500 & & 117 \\
\hline AtCYS-5 & At5g 47550 & & 127 \\
\hline AtCYS-6 & At3g12490 & & 233 \\
\hline AtCYS-7 & At5g05110 & $\left.[\mathbf{D V}]_{228}^{240} \square\right]_{122}^{179} \square$ & 229 \\
\hline
\end{tabular}

Fig. 1 Genomic organization of the cystatin genes of rice (OC-I to OC-XII) and Arabidopsis (AtCYS-1 to AtCYS-7). Exons are indicated by boxes and introns by lines. The lengths of introns are given (in bp). The LARFAV motif and the active-site QxVxG motifs are represented as cross-hatched and black boxes, respectively

Genomic organisation of cystatin genes in Arabidopsis, rice and barley

The structure of the genes for the 12 rice and seven Arabidopsis cystatins, and their chromosomal location, was determined from the genomic sequences of $O$. sativa ssp. japonica and A. thaliana (Fig. 1). Structural examination revealed that in genes for three cystatins from rice (OC-I, OC-II and OC-III) and three from Arabidopsis (AtCYS-1, AtCYS-2 and AtCYS-3) one intron was present between the sequences encoding the conserved LARFAV and the active-site QxVxG motifs. Eight cystatin sequences from rice (OC-IV to OC-XI) and two from Arabidopsis (AtCYS-4 and AtCYS-5) had no introns in their ORFs. The longest coding sequences, one from rice (OC-XII) and two from Arabidopsis (AtCYS6 and AtCYS-7), each had three introns. The cystatin sequences were shown to be distributed on five of the 12 rice chromosomes and on four out of the five Arabidopsis chromosomes (Fig. 2). Tandemly arranged sequences indicative of recent duplication events were found on rice chromosomes 1 (OC-IV and OC-V) and 3 (OC-VI, OC-VII and OC-IX).

Table 1 Barley cystatins defined in this study

\begin{tabular}{llll}
\hline Name & Accession No. & Cultivar & Length \\
\hline HvCPI-1 & Y12068 & Bomi & 107 \\
HvCPI-2 & AJ748337 & Morex & 140 \\
HvCPI-3 & AJ748338 & Morex & 145 \\
HvCPI-4 & AJ748344 & Morex & 169 \\
HvCPI-5 & AJ748340 & Morex & 147 \\
HvCPI-6 & AJ748341 & Morex & 123 \\
HvCPI-7 & AJ748345 & Morex & 124 \\
\hline
\end{tabular}


The gene for HvCPI-1 of barley was previously found to have a single intron (Martínez et al. 2005) in the same position as that in its orthologue OC-II from rice. Preliminary PCR experiments using total DNA from barley (cv. Bomi) leaves, and sequence comparisons with corresponding DNA fragments amplified from ESTs for HvCPI-2 to HvCPI-7, allowed us to detect introns in three genes (those for HvCPI-2, HvCPI-3 and Hv-CPI4), and to establish that the genes for HvCPI-5, HvCPI-6 and HvCPI-7 have no introns (data not shown).

Phylogenetic analysis of cystatin families in Arabidopsis, rice and barley

In order to evaluate the evolutionary relationships among the cystatin proteins, the deduced amino acid sequences of the cystatins identified in rice ssp. japonica and Arabidopsis, and the seven cystatins from barley (six ESTs annotated from cv. Morex plus HvCPI-1 from cv. Bomi) were compared (see Electronic Supplementary Material for the complete alignment), and an unrooted phylogenetic tree was constructed by the neighbourjoining method (Fig. 3). The minimum number of amino acid identities $(6 \%)$ was found for the comparisons HvCPI-1/OC-III and OC-IX/OC-III, whereas the maximum number of identities was observed for the HvCPI4/OC-XII cystatin pair $(85 \%)$. The average value for all the PhyCys identified was $29.46 \%$. The tree was organized in three major clusters of orthologous genes (MCOGs), A-C. The bootstrap values for the main subgroups (A2, B1, B2, C1.1, C1.2 and C2) were higher than $50 \%$, suggesting that these represent true clusters of cystatins that share a similar origin. Five pairs of orthologous proteins in rice and barley could be identified: HvCPI-2/OC-I, HvCPI-1/OC-II, HvCPI-4/OCXII, HvCPI-3/OC-III, and HvCPI-6/OC-VIII. The

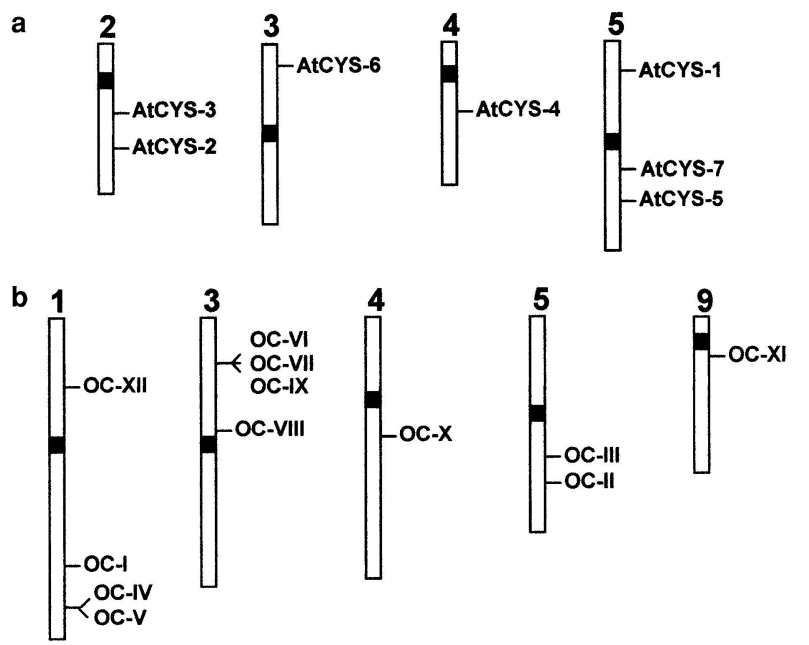

Fig. 2 a, b Chromosomal distribution of cystatin genes in Arabidopsis (a) and rice (b). The centromeres are represented by the black boxes protein HvCPI-5 of barley is a putative orthologue of two rice cystatins, OC-IV and OC-V, which are encoded by adjacent genes derived from a recent duplication event. However, no clear homologue for HvCPI-7 in the subgroup $\mathrm{C} 1.2$ could be identified in rice. Rice proteins OC-VI, OC-VII, and OC-IX, which are encoded by contiguous genes on rice chromosome 3 , are clustered in the same C1.2 subgroup, but they are not so closely related to $\mathrm{Hv}-\mathrm{CPI}-7$ as to be considered orthologues of the latter. The Arabidopsis proteins are more dispersed in the tree, and it is more difficult to determine their orthologous partners in rice and barley, indicating rapid evolution of the gene family after the monocot-dicot split.

Structural comparisons of cystatins from rice, Arabidopsis and barley

A schematic alignment of the deduced amino acid sequences of the cystatins of rice ssp. japonica, barley, and Arabidopsis is shown in Fig. 4. The SignalP software predicted a signal peptide of 16-40 amino acids for all the sequences - with two exceptions, barley HvCPI-1 and Arabidopsis AtCYS-1, both of which belong to MCOG A. The previously described phytocystatin

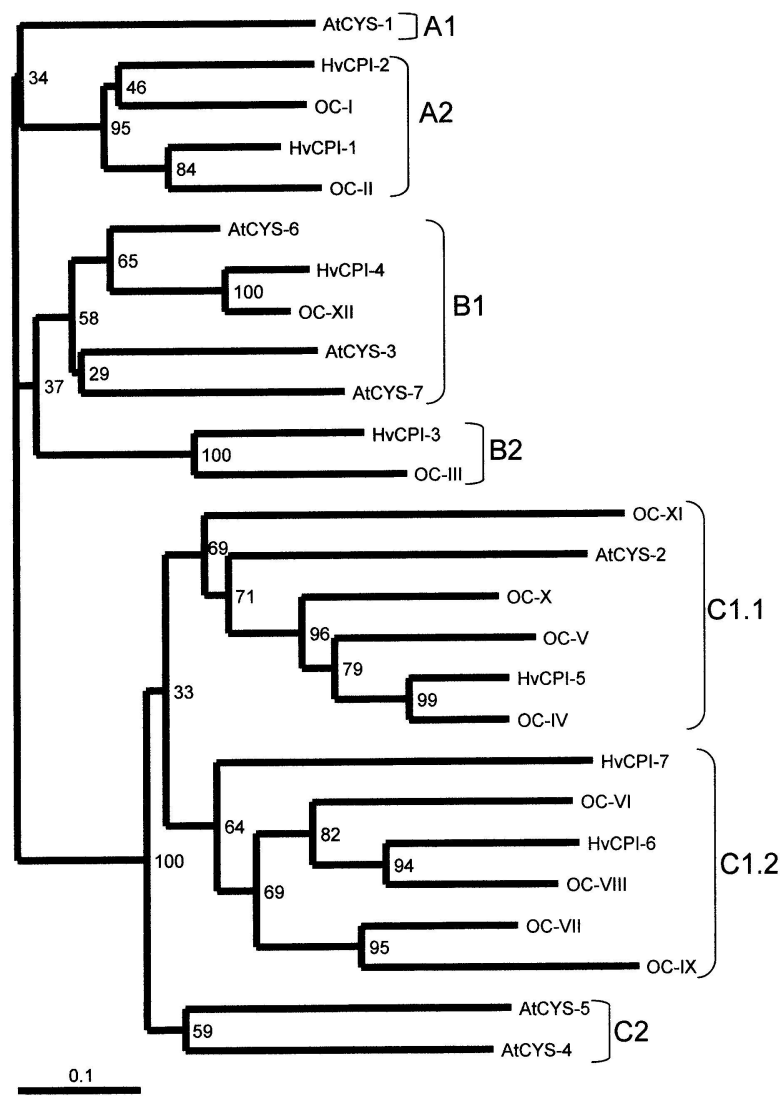

Fig. 3 Unrooted phylogenetic tree of the rice, barley and Arabidopsis cystatins constructed by the neighbour-joining method. Bootstrapping values are indicated as percentages. The major clusters of homologous genes identified are indicated 
Fig. 4 Schematic alignment of the deduced amino acid sequences of the rice, barley and Arabidopsis cystatins. The predicted signal peptide $(S P)$ and the $\mathrm{C}$-terminal tails $(C$-term) are shaded. The approximate locations of the five $\beta$-sheets and the single $\alpha$-helix are indicated

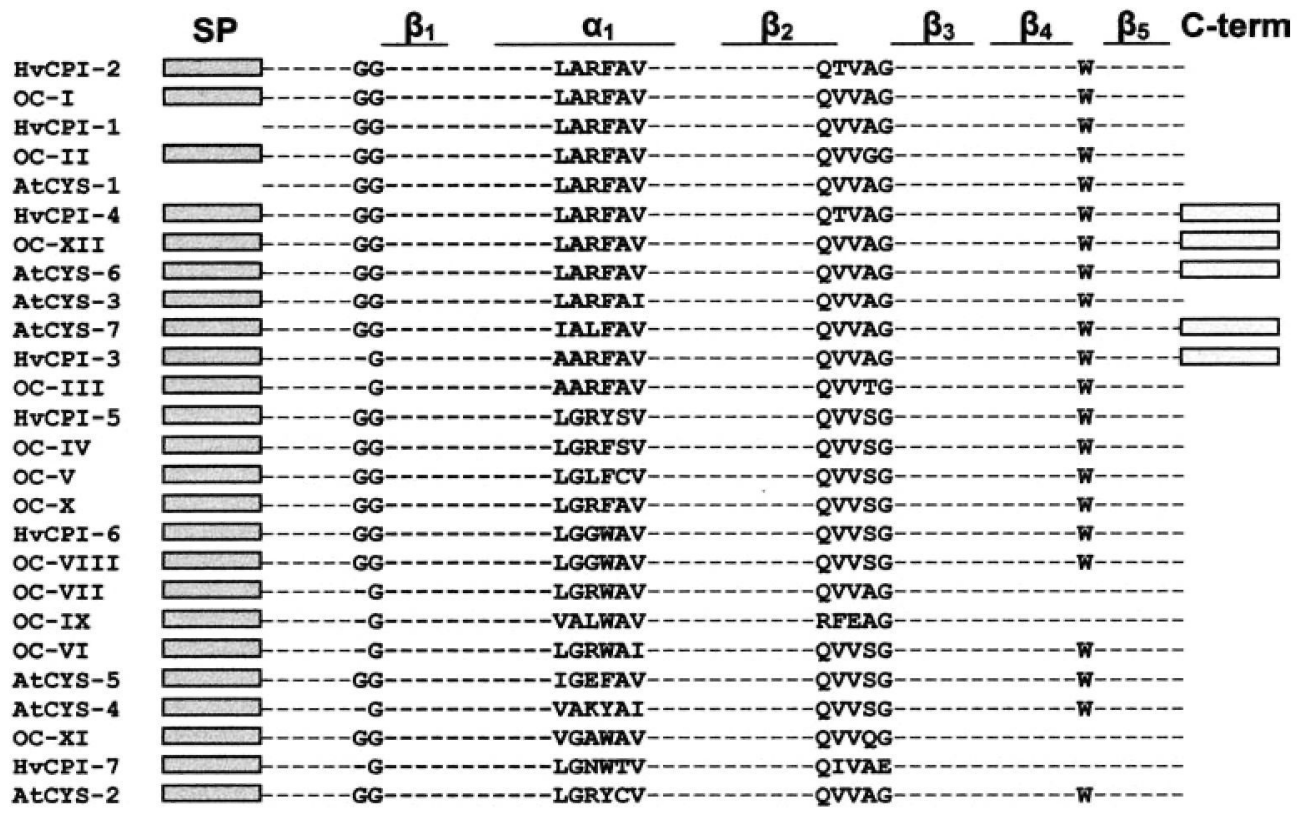

of OC-I (Nagata et al. 2000). Some other motifs (7-26; Table 2 and Fig. 6) may be used to group these plant cystatins into subfamilies or to search for remote homologies. Cystatins can be assigned to the different clusters of orthologous genes according to the motif present between the first $\beta$-sheet and the $\alpha$-helix. Thus, motifs $22,20,25$, and 15 are characteristic of the subgroups $\mathrm{A} 2, \mathrm{~B} 1, \mathrm{C} 1.1$ and $\mathrm{C} 1.2$, and $\mathrm{C} 2$, respectively. Other remote homologies could be deduced for cystatins of MCOG A and B because they share the motif 26, and for the cystatins that share motif $11,14,16,18$ or 21 but belong to different branches of the phylogenetic tree. Finally, the four longest cystatins with C-terminal extensions share different motifs in their tails (motifs 6-10, 12, 13 , and 17), which further supports a common origin for these proteins. Likewise, the occurrence of motif 6 in these tails in a location similar to the main body of the protein is in agreement with a cystatin-like assignment to these tails. However, the C-terminal extension in HvCPI-3 does not share any of these motifs, indicating a different phylogenetic origin for this cystatin. nal tails include motifs that are recognised as characteristic of the other cystatins in the Pfam databank, suggesting that they may have arisen by internal duplication with subsequent divergence, as the typical cystatin motifs are difficult to recognise. The fifth sequence (HvCPI-3) has a shorter C-terminal tail which shows no sequence similarity to the other four, belongs to the subgroup B2 of the phylogenetic tree, and appears to be the orthologue of rice OC-III, which could indicate a different origin for this cystatin (Fig. 5).

Comparative analysis of the amino acid sequences using the MEME software discovered several conserved motifs (Table 2 and Fig. 6). Almost all the sequences share the motifs $1-6$, which span the first loop and the third $\beta$-sheet, the fourth $\beta$-sheet and the second loop, the $\alpha$-helix, the second $\beta$-sheet, the fifth $\beta$-sheet, and the first $\beta$-sheet, respectively, of the three-dimensional structure

\section{EST-derived expression data}

To complement the structural data obtained for these gene products, indirect information on cellular function can be obtained from the spatial and temporal expression profiles of their coding genes. Expressed sequence tags (ESTs) provide a useful means of studying mRNA expression profiles (digital northerns). At the time of the analysis, the GenBank EST database contained 299,998 rice ESTs, 375,610 barley ESTs and 326,202 Arabidopsis ESTs. This database was searched with the amino acid sequence of each cystatin using the tblastn program, and the resulting accessions were classified according to the source tissue from which the cDNA libraries derived. 
Fig. 5 a, b Sequence

comparisons of the cystatins

from Arabidopsis, rice and

barley. a Alignment of the

C-terminal extensions present

in five cystatins. The amino acid

conserved in the four longest

proteins is indicated by an

asterisk and strong and weak

conservative changes are

marked by colons and dots,

respectively. b Pairwise

sequence similarity values for

barley, rice and Arabidopsis

cystatins based on their

deduced full-length sequences

and on their C-terminal

extensions

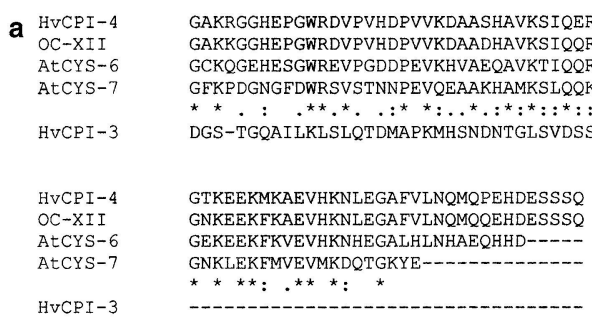

Pairwise \% similarity whole deduced protein

b

\begin{tabular}{lcccccc}
\cline { 3 - 7 } & & A & B & C & D & E \\
\hline Barley HvCPI-4 & A & & 85 & 57 & 42 & 31 \\
Rice OC-XII & B & 92 & & 60 & 43 & 31 \\
Arabidopsis AtCYS-6 & C & 62 & 67 & & 45 & 30 \\
Arabidopsis AtCYS-7 & D & 48 & 51 & 44 & & 25 \\
Barley HvCPI-3 & E & 7 & 12 & 7 & 9 &
\end{tabular}

Pairwise \% similarity 3 'tail
The results obtained were summarized as presence/absence of ESTs in four main tissues (leaf, root, flower, and seed) of Arabidopsis, barley, and rice (Table 3). Expression of the rice OC-I, the barley HvCPI-3 and the Arabidopsis AtCYS-1 and AtCYS-6 cystatins was detected in all four tissues, while other cystatins were found to have more restricted expression profiles. Six of the cystatin genes of rice were not represented in the EST collection.

\section{Discussion}

Although sequence comparisons within plant multigene families encoding hydrolase inhibitors were performed in the pre-genomic era (Garcia-Olmedo et al. 1987; Carbonero et al. 1993), the availability of complete genome sequences markedly extends the scope of this type of study. Thus, the structural diversity and organization of three gene families coding for serine protease inhibitors of the Kunitz-type from potato tubers, and of the Bowman-Birk type from sugarcane, as well as the molecular evolution of the latter in flowering plants, have been reported recently (Ishikawa et al. 1994; Heibges et al. 2003; Mello et al. 2003).

We present here the first comparative phylogenetic analysis of cystatin gene families from Arabidopsis, rice and barley. Considering the extensive annotation work done in rice and Arabidopsis since the release of their sequenced genomes (The Arabidopsis Genome Initiative
Fig. 6 Identification and distribution of conserved motifs identified by the MEME software in the cystatins of rice, barley and Arabidopsis. The location of each cystatin in the phylogenetic tree and the relationship between the predicted location of these motifs and the main regions and conserved motifs of the cystatin proteins are indicated. SP, signal peptide

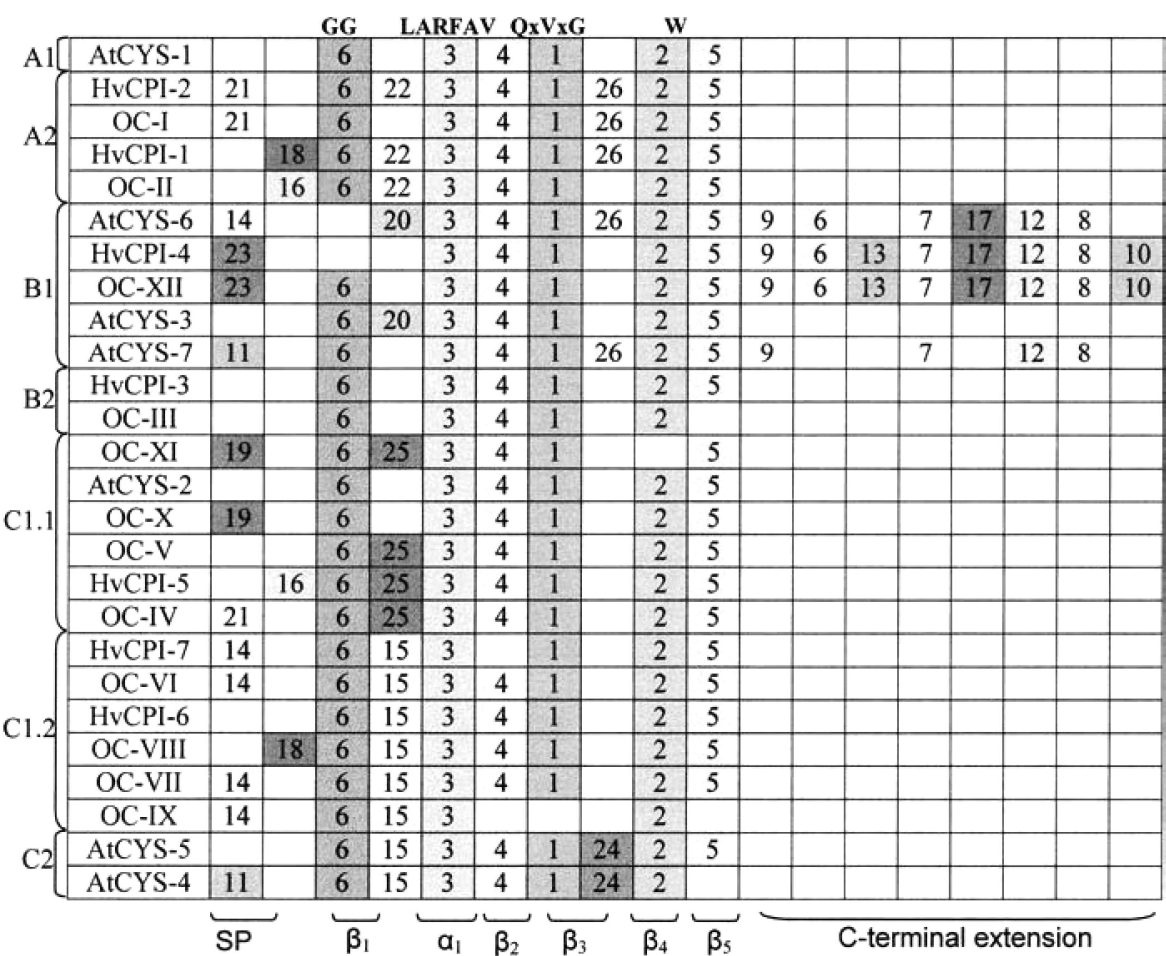


Table 2 Conserved motifs identified in cystatins from Arabidopsis, rice and barley by the MEME system

\begin{tabular}{lll}
\hline Motif $^{\text {a }}$ & Length (residues) & Sequence \\
\hline 1 & 12 & QVVSGTMYYLTI \\
2 & 12 & YEAKVWEKPWMN \\
3 & 12 & QDLGRFCVDEHN \\
4 & 11 & LEFERVVKAKQ \\
5 & 11 & FKQLQSFKPAH \\
6 & 11 & RGMHLGGWTPI \\
7 & 12 & SIQQRSNSLFPY \\
8 & 12 & KEEKFKVEVHKN \\
9 & 11 & PSFTISDLGCK \\
10 & 12 & NQMQPEHDESSS \\
11 & 9 & MCMMLICIS \\
12 & 12 & KFDILMKLKRGN \\
13 & 11 & HDPVVKDAADH \\
14 & 9 & MRTSSLLLI \\
15 & 8 & KNVSDPHI \\
16 & 8 & RRRCPRLA \\
17 & 12 & ELIEIVRAKAEV \\
18 & 8 & AQGGGNRG \\
19 & 8 & MARHPMLF \\
20 & 8 & RGNQNTRE \\
21 & 8 & MWKYCPIG \\
22 & 8 & PAGRENDL \\
23 & 8 & TRPVSSSP \\
24 & 8 & DGDGKIKN \\
25 & 8 & RDVEGDNQ \\
26 & 8 & RVKEGGTK \\
\hline & &
\end{tabular}

${ }^{a}$ Numbers correspond to the motifs described in Fig. 4
Table 3 EST-derived expression profiles based on digital northern analysis

\begin{tabular}{|c|c|c|c|c|}
\hline \multirow[t]{2}{*}{ Gene product } & \multicolumn{4}{|l|}{ Tissue $^{a}$} \\
\hline & Flower & Leaf & Root & Seed \\
\hline OC-I & + & + & + & + \\
\hline OC-II & + & + & + & - \\
\hline OC-III & + & + & - & - \\
\hline OC-IV & - & - & - & - \\
\hline OC-V & - & - & - & - \\
\hline OC-VI & - & - & - & - \\
\hline OC-VII & - & - & - & - \\
\hline OC-VIII & - & + & - & + \\
\hline OC-IX & - & - & - & - \\
\hline OC-X & - & + & + & - \\
\hline OC-XI & - & - & - & - \\
\hline OC-XII & - & + & - & + \\
\hline AtCYS-1 & + & + & + & + \\
\hline AtCYS-2 & - & - & - & + \\
\hline AtCYS-3 & - & + & - & - \\
\hline AtCYS-4 & + & + & + & - \\
\hline AtCYS-5 & + & - & - & + \\
\hline AtCYS-6 & + & + & + & + \\
\hline AtCYS-7 & + & + & - & - \\
\hline HvCPI-1 & - & + & + & + \\
\hline HvCPI-2 & - & + & + & + \\
\hline HvCPI-3 & + & + & + & + \\
\hline $\mathrm{HvCPI}-4$ & + & + & - & + \\
\hline HvCPI-5 & - & - & - & + \\
\hline HvCPI-6 & - & - & - & + \\
\hline HvCPI-7 & - & - & - & + \\
\hline
\end{tabular}

${ }^{\text {a }}$ Presence $(+)$ or absence $(-)$ of gene sequences in EST collections derived from the indicated tissues

2000; Goff et al. 2002; Yu et al. 2002), as well as the analysis of the CUGI barley EST collection presented in this study, we assume that all (or nearly all) of the cystatins from rice and Arabidopsis, and at least one member of each group of cystatins from barley, are represented among the 26 sequences documented here ( 7 from Arabidopsis, 12 from rice, and 7 from barley).

Of the seven annotated Arabidopsis cystatins that have been included in this study, only one, AtCYS-1, has been functionally characterized at the molecular level, and a putative role as a suppressor of hypersensitive cell death has been assigned to it (Belenghi et al. 2003). In rice, the number of predicted cystatins is twelve. Two of these cystatins, OC-I and OC-II, were among the first cystatin proteins to be purified. Both are expressed in the rice seed, and the three-dimensional structure of OC-I has been established. Experimental evidence suggests that they play a double role: as endogenous regulators and as defence proteins against insect pests (Abe et al. 1987, 1991; Kondo et al. 1990; Kuroda et al. 1996; Nagata et al. 2000; Arai et al. 2002). In barley, only one of the seven cystatins annotated, HvCPI-1, the orthologue of OC-II, has been extensively characterized (Gaddour et al. 2001; Martínez et al. 2003a, 2003b, 2005). Its mRNA is expressed in developing and germinating seeds, and in vegetative tissues, where it is induced by cold temperatures and anaerobiosis and is under circadian control in leaves. Moreover, HvCPI-1 is a strong inhibitor of several pathogenic fungi. Thus, a dual role can be assigned to it, as in the case of its orthologue in rice. The digital northern analysis included in this study indicates a tissue-specific expression pattern for some cystatins, whereas others are ubiquitously expressed and several rice cystatins seem not to be expressed at all. However, these data must be interpreted with caution, since the number of ESTs scanned was not sufficient, for example, to detect the expression of OC-II in seeds, which has been convincingly documented by more direct methods (Arai et al. 2002).

The motifs discovered by MEME analysis in PhyCys indicate that they may all share the three-dimensional structure of OC-I, since the residues that constitute the five $\beta$-sheets and the $\alpha$-helix are quite conserved. Likewise, the CLUSTAL alignment suggests strong conservation of the motifs involved in the interaction with cysteine proteinases. These results indicate that phytocystatins are a highly conserved family of proteins. However, the phytocystatins examined in this study differ from one another in other respects. All the PhyCys studied, with two exceptions (HvCPI-1 and AtCYS-1), have predicted signal peptides, which suggests that they are targeted to the endoplasmic reticulum. Four cystatin sequences have C-terminal tails that are recognized as cystatin domains by the Pfam program, suggesting that they probably originated by a duplication event. However, the cystatin motifs that interact with the cysteine 
proteinases are not conserved in these tails, which may indicate that these regions have evolved to take on a different role. There are also variations in the motifs that interact with the cysteine proteinases in the main body of several barley, rice, and Arabidopsis cystatins. The G residue in the $\mathrm{N}$-terminal region is well conserved, and a GG motif is often present. Phage display experiments have been performed with human cystatin $\mathrm{A}$. In these studies the four $\mathrm{N}$-terminal amino acids were randomly mutated and the resulting variants were expressed on the surface of the filamentous phage, and screened for binding to papain. Most of the variants that bound to the protease were found to have a glycine residue in position 4 (Ylinenjarvi et al. 1999). Moreover, the glycine residue at position 10 of oryzacystatin-I was shown to be important for its inhibitory activity (Urwin et al. 1995). The importance of the tryptophan residue in the second loop has been confirmed by phage display experiments with a soyacystatin: all the variants selected based on affinity for immobilized papain had a $\mathrm{W}$ in this second loop (Koiwa et al. 2001). However, four putative cystatins from rice and barley (OC-VII, OC-IX, OC-XI, and $\mathrm{HvCPI}-7$ ) lack this tryptophan. It will be interesting to test the inhibitory effect of these proteins on cysteine proteinases. Moreover, two PhyCys with variations in the active site $\mathrm{QxVxG}$ have been found. These are OCIX (RFEAG) and HvCPI-7 (QIVAE). The variation in the active site of OC-IX seems more drastic than that in HvCPI-7. In this context, it is worth mentioning that Arai et al. (1991) found that replacement of the V residue in the active site of OC-I had no effect on the binding of papain. In phage display experiments, Koiwa et al. (2001) did not find any binding variants in this region, but Melo et al. (2003) - using the same technique-found two different variants of this motif, DVVSA and NTSSA, with a lower affinity for papain but a similar inhibitory effect against a cysteine proteinase from the coleopteran insect Acanthoscelides $o b$ tectus. Thus, variants of the active-site motif may be associated with different inhibitory properties against different cysteine proteinases.

With respect to their intron-exon structure, three main types of cystatin genes can be defined. Those that have no introns in their ORFs all belong to MCOG C, those with three introns fall into subgroup B1, and those with only one intron in the DNA sequence-located between the sequences coding for the conserved motifs LARFAV and $\mathrm{QxVxG}$ - are clustered in MCOG A or in subgroup B2, although this intron is also found in the AtCYS-2 protein which is a member of MCOG C. No correspondence between EST-derived tissue-specific expression data and MCOGs could be detected. However, the fact that the majority of the cystatins presenting significant variations in the first and the second loop are cereal cystatins with no clear homology between rice and barley supports the idea that these cystatins have evolved rapidly to inhibit specific cysteine proteinases, probably providing protection against species-specific pests. OC-VI, OC-VII, OC-IX, OC-XI, and HvCPI-7 in
MCOG $\mathrm{C}$ are examples of this specialized evolution. In contrast, the cystatins of MCOGs A and B present clear homologies between rice and barley, and even Arabidopsis. These findings suggest that they are more ancient proteins that are probably involved in the endogenous regulation of cysteine proteinases in the plant, though they could also have a non-specific role in plant defence against phytopathogenic pests, as has been demonstrated for the barley HvCPI-1 protein (Martínez et al. 2003a, b).

In conclusion, although only seven cystatin genes have been annotated in barley, the actual number of expected genes in this member of the Triticeae is probably similar to that obtained for rice, and higher than the number found in Arabidopsis. The existence of more cystatin proteins in the cereals than in Arabidopsis could be of evolutionary significance, and could be a defence mechanism used by these species against the wide variety of pests that attack them. The clusters of orthologous groups discovered in this study may facilitate the assignment of specific roles to cystatins of unknown function as new information is obtained from the genomes of other crops.

We thank Mar Gonzalez for technical assistance. Financial support from the Comunidad Autónoma de Madrid, Spain (07M/0050/2002) and the Ministerio de Ciencia y Tecnología, Spain (AGL03-0335) are gratefully acknowledged. M. Martínez holds a Ramón y Cajal Contract awarded by the Ministerio de Ciencia y Tecnología (Spain). Z. Abraham was the recipient of a post-doctoral fellowship from the Comunidad Autónoma de Madrid (Spain). This work has been carried out in compliance with the current laws governing genetic experimentation in Spain

Abe K, Emori Y, Kondo H, Suzuki K, Arai S (1987) Molecular cloning of a cysteine proteinase inhibitor of rice (oryzacystatin). J Biol Chem 262:16793-16797

Abe K, Kondo H, Watanabe H, Emori Y, Arai S (1991) Oryzacystatins as the first well-defined cystatins of plant origin and their target proteinases in rice seeds. Biomed Biochim Acta $50: 637-641$

Arai S, Watanabe H, Kondo H, Emori Y, Abe K (1991) Papaininhibitory activity of oryzacystatin, a rice seed cysteine proteinases inhibitor, depends on the central Gln-Val-Val-Ala-Gly region conserved among cystatin superfamily members. J Biochem 109:294-298

Arai S, Matsumoto I, Emori Y, Abe K (2002) Plant seed cystatins and their target enzymes of endogenous and exogenous origin. J Agr Food Chem 50:6612-6617

Atkinson HJ, Urwin PE, McPherson MJ (2003) Engineering plants for nematode resistance. Ann Rev Phytopathol 41:615-639

Bailey TL, Elkan C (1994) Fitting a mixture model by expectation maximization to discover motifs in biopolymers. Proc Int Conf Intell Syst Mol Biol 2:28-36

Belenghi B, Acconcia F, Trovato M, Perazzolli M, Bocedi A Polticelli F, Ascenzi P, Delledonne M (2003) AtCYS1, a cystatin from Arabidopsis thaliana, suppresses hypersensitive cell death. Eur J Biochem 270:2593-2604

Bendtsen JD, Nielsen H, von Heijne G, Brunak S (2004) Improved prediction of signal peptides: SignalP 3.0. J Mol Biol 340:783795 
Brown WM, Dziegielewska KM (1997) Friends and relations of the cystatin superfamily-new members and their evolution. Protein Sci $6: 5-12$

Carbonero P, Salcedo G, Sanchez-Monge R, Garcia-Maroto F, Gomez L, Medina J, Mena M, Diaz I (1993) A multigene family from cereals which encodes inhibitors of trypsin and heterologous $\alpha$-amylases. In: Aviles FX (ed) Innovations of proteases and their inhibitors. Walter de Gruyter, Berlin-New York, pp 333-348

Corre-Menguy F, Cejudo FJ, Mazubert C, Vidal J, LelandaisBriere C, Torres G, Rode A, Hartmann C (2002) Characterization of the expression of a wheat cystatin gene during caryopsis development. Plant Mol Biol 50:687-698

Delledonne $M$, Allegro $G$, Belenghi $B$, Balestrazzi A, Picco $F$, Levine A, Zelasco S, Calligari P, Confalonieri M (2001) Transformation of white poplar (Populus alba L.) with a novel Arabidopsis thaliana cysteine proteinase inhibitor and analysis of insect pest resistance. Mol Breed 7:35-42

Gaddour K, Vicente-Carbajosa J, Lara P, Isabel-Lamoneda I, Díaz I, Carbonero P (2001) A constitutive cystatin-encoding gene from barley (Icy) responds differentially to abiotic stimuli. Plant Mol Biol 45:599-608

Garcia-Olmedo F, Salcedo G, Sanchez-Monge R, Gomez L, Royo J, Carbonero P (1987) Plant proteinaceous inhibitors of proteinases and $\alpha$-amylases. In: Miflin B (ed) Oxford Surveys of Plant Molecular and Cell Biology, vol 4. Oxford University Press, Oxford, pp 275-334

Goff SA et al (2002) A draft sequence of the rice genome (Oryza sativa L. ssp. japonica). Science 296:92-100

Gutierrez-Campos R, Torres-Acosta J, Saucedo-Arias LJ, GomezLim MA (1999) The use of cysteine proteinase inhibitors to engineer resistance against potyviruses in transgenic tobacco plants. Nat Biotechnol 17:1223-1226

Haq SK, Atif SM, Khan RH (2004) Protein proteinase inhibitor genes in combat against insects, pests, and pathogens: natural and engineered phytoprotection. Arch Biochem Biophys 431:145-159

Heibges A, Glaczinski H, Ballvora A, Salamini F, Gebhardt C (2003) Structural diversity and organization of three gene families for Kunitz-type enzyme inhibitors from potato tubers (Solanum tuberosum L.). Mol Gen Genomics 269:526-534

Higgins D, Thompson J, Gibson T, Thompson JD, Higgins DG, Gibson TJ (1994) CLUSTAL W: improving the sensitivity of progressive multiple sequence alignment through sequence weighting, position-specific gap penalties and weight matrix choice. Nucleic Acids Res 22:4673-4680

Ishikawa A, Ohta S, Matsuoka K, Hattori T, Nakamura K (1994) A family of potato genes that encoded Kunitz-type proteinase inhibitors: structural comparisons and differential expression. Plant Cell Physiol 35:303-312

Koiwa H, D'Urzo MP, Assfalg-Machleidt I, Zhu-Salzman K, Shade RE, An H, Murdock LL, Machleidt W, Bressan RA, Hasegawa PM (2001) Phage display selection of hairpin loop soyacystatin variants that mediate high affinity inhibition of a cysteine proteinase. Plant $\mathbf{J}$ 27:383-391

Kondo H, Abe K, Nishimura I, Watanabe H, Emori Y, Arai S (1990) Two distinct cystatin species in rice seeds with different specificities against cysteine proteinases. $\mathrm{J}$ Biol Chem 265:15832-15837

Kuroda M, Ishimoto M, Suzuki K, Kondo H, Abe K, Kimura K, Arai S (1996) Oryzacystatins exhibit growth-inhibitory and lethal effects on different species of bean insect pests, Callosobruchus chinensis (Coleoptera) and Riptortus calavatus (Hemiptera). Biosci Biotech Biochem 60:209-212

Kuroda M, Kiyosaki T, Matsumoto I, Misaka T, Arai S, Abe K (2001) Molecular cloning, characterization and expression of wheat cystatins. Biosci Biotechnol Biochem 65:22-28

Lim CO, Lee SI, Chung WS, Park SH, Hwang I, Cho MJ (1996) Characterization of a cDNA encoding cysteine proteinase inhibitor from Chinese cabbage (Brassica campestris L. ssp. pekinensis) flower buds. Plant Mol Biol 30:373-379
Margis R, Reis EM, Villeret V (1998) Structural and phylogenetic relationship among plant and animal cystatins. Arch Biochem Biophys 359:24-30

Martínez M, López-Solanilla E, Rodriguez-Palenzuela P, Carbonero P, Díaz I (2003a) Inhibition of plant phytopathogenic fungi by the barley cystatin Hv-CPI (gene Icy) is not associated with its cysteine-proteinase inhibitory properties. Mol PlantMicrobe Interact 16:876-883

Martínez M, Rubio-Somoza I, Carbonero P, Díaz I (2003b) A cathepsin B-like cysteine protease gene from Hordeum vulgare (gene $C a t B$ ) induced by GA in aleurone cells is under circadian control in leaves. J Exp Bot 54:951-959

Martínez M, Rubio-Somoza I, Fuentes R, Lara P, Carbonero $\mathbf{P}$ Diaz I (2005) The barley cystatin gene (Icy) is regulated by DOF transcription factors in aleurone cells upon germination. J Exp Bot 56:547-556

Mello MO, Tanaka AS, Silva-Filho MC (2003) Molecular evolution of Bowman-Birk type proteinases inhibitors in flowering plants. Mol Phylogenet Evol 27:103-112

Melo FR, Mello MO, Franco OL, Rigden DJ, Mello LV, Genú AM, Silva-Filho MC, Gleddie S, Grossi-de-Sá MF (2003) Use of phage display to select novel cystatins specific for Acanthoscelides obtectus cysteine proteinases. Biochim Biophys Acta 1651:146-152

Misaka T, Kuroda M, Iwabuchi K, Abe K, Arai S (1996) Soyacystatin, a novel cysteine proteinase inhibitor in soybean, is distinct in protein structure and gene organization from other cystatins of animal and plant origin. Eur J Biochem 240:609614

Nagata K, Kudo N, Abe K, Arai S, Tanokura M (2000) Threedimensional solution of oryzacystatin-I, a cysteine proteinase inhibitor of rice, Oryza sativa L. japonica. Biochemistry 39:14753-14760

Page RDM (1996) TREEVIEW: an application to display phylogenetic trees on personal computers. Comput Appl Biosci $12: 357-358$

Pernas M, Sanchez-Monge R, Gomez L, Salcedo G (1998) A chestnut seed cystatin differentially effective against cysteine proteinases from closely related pests. Plant Mol Biol 38:12351242

Pernas M, López-Solanilla E, Sanchez-Monge R, Salcedo G, Rodriguez-Palenzuela P (1999) Antifungal activity of a plant cystatin. Mol Plant-Microbe Interact 12:624-627

Pernas M, Sanchez-Ramos I, Sanchez-Monge R, Lombardero M, Arteaga C, Castañera P, Salcedo G (2000) Der pl and Der fl, the highly related and major allergens from house mites, are differentially affected by a plant cystatin. Clin Exp Allergy 30:972-978

Shyu DJ, Chou WM, Yiu TJ, Lin CP, Tzen JT (2004) Cloning, functional expression, and characterization of cystatin in sesame seed. J Agric Food Chem 52:1350-1356

Siqueira-Junior CL, Fernandes KVS, Machado OLT, Cunha M, Gomes VM, Moura D, Jacinto T (2002) 87-kDa tomato cystatin exhibits properties of a defence protein and forms crystals in prosystemin over-expressing transgenic plants. Plant Physiol Biochem 40:247-254

Soares-Costa A, Beltramini LM, Thiemann OH, Enrique-Silva F (2002) A sugarcane cystatin: recombinant expression, purification and antifungal activity. Biochem Biophys Res Commun 296:1194-1199

Solomon M, Belenghi B, Delledonne M, Levine A (1999) The involvement of cysteine proteases and protease inhibitor genes in programmed cell death in plants. Plant Cell 11:431444

The Arabidopsis Genome Initiative (2000) Analysis of the genome sequence of the flowering plant Arabidopsis thaliana. Nature 408:796-815

Urwin PE, Atkinson HJ, McPherson MJ (1995) Involvement of the $\mathrm{NH}_{2}$-terminal region of oryzacystatin-I in cysteine proteinases inhibition. Protein Eng 8:1303-1307 
Vain P, Worland B, Clarke MC, Richard G, Beavis M, Liu H, Kholi A, Leech M, Snape J, Christou P, Atkinson HJ (1998) Expression of an engineered cysteine proteinase inhibitor (Oryzacystatin-I $\Delta$ D86) for nematode resistance in transgenic plants. Theor Appl Genet 96:266-271

Waldrom C, Wegrich LM, Merlo PAO, Walsh TA (1993) Characterization of a genomic sequence coding for potato multicystatin, an eight-domain cysteine proteinase inhibitor. Plant Mol Biol 23:801-812

Walker AJ, Urwin PE, Atkinson HJ, Brain P, Glen DM, Shewry PR (1999) Transgenic Arabidopsis leaf tissue expressing a modified oryzacystatin shows resistance to the field slug Deroceras reticulatum (Muller). Transgenic Res 8:95-103
Wu J, Haard NF (2000) Purification and characterization of a cystatin from the leaves of methyl jasmonate treated tomato plants. Comp Biochem Physiol C Toxicol Pharmacol 127:209220

Ylinenjarvi K, Widersten M, Bjork I (1999) Hydrophobic sequences can substitute for the wild-type N-terminal sequence of cystatin A (stefin A) in tight binding to cysteine proteinases: selection of high-affinity $\mathrm{N}$-terminal region variants by phage display. Eur J Biochem 261:682-688

$\mathrm{Yu} \mathbf{J}$ et al (2002) A draft sequence of the rice genome (Oryza sativa L. ssp. indica). Science 296:79-92 